Erratum

\title{
Actin stringently accumulated in the specifically positioned, differentiating female gametangia of Allomyces
}

B.N. Nguyen Thi and G. Turian

Laboratory of General Microbiology, Sciences III, Université de Genève, CH-1211 Geneva 4, Switzerland

Sex Plant Reprod (1992) 5:310-312

In this article, the second sentence of the Summary should have read:

"The anti-actin, cytochalasin D, can selectively suppress female differentiation in both species." 